
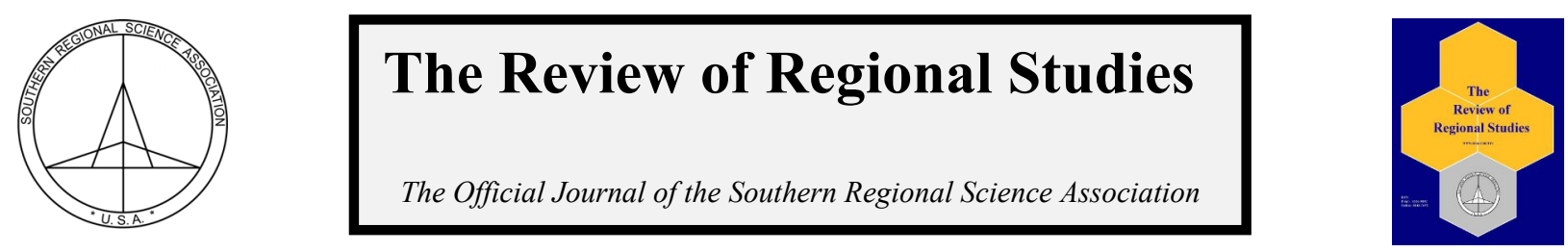

\title{
Economic Complexity and Regional Growth Performance: Evidence from the Mexican Economy*
}

\author{
Juan Carlos Chávez a , Marco T. Mosqueda ${ }^{\mathrm{a}}$, and Manuel Gómez-Zaldívara,b \\ ${ }^{a}$ Dirección General de Investigación Económica, Banco de México \\ ${ }^{b}$ Department of Economics and Finance, University of Guanajuato, Mexico
}

\begin{abstract}
This paper uses information on the productive structure of each of Mexico's states to calculate a measure of economic complexity using the Method of Reflections proposed by Hausmann and Hidalgo (2009). The results suggest that the country's states differ markedly in terms of the activities they specialize in, and therefore also in terms of their economic complexity. There is also a clear regional pattern which shows that states in the north are more complex, those in the central region have an intermediate level of complexity, and those in the south have the lowest levels of complexity. As previous international studies have shown, complexity is an important factor in explaining the economic disparities observed in the country, given that its measure is positively related to both the level of wealth and the growth rate of the states. Therefore, we can assert that the dispersion of productive knowledge - measured according to the specialization of the states or the location of the various economic activities performed there - goes some way toward explaining their different patterns of growth.
\end{abstract}

Keywords: diversity, ubiquity, economic complexity, economic growth, Mexican states

JEL Codes: O14, O47, R11

\section{INTRODUCTION}

Over the last three decades, Mexico has reformed its economy, making it more marketoriented in order to boost economic growth. ${ }^{1}$ Still, it has consistently failed to reach its growth goals. Moreover, economic performance at the national level does not necessarily match what is happening at the regional level, where the performance of the states is very heterogeneous. On the one hand, there are thriving regions where newly developed industries that rely on a high level of technology and skilled labor have been the key to improving the level of progress of the states where these are located, since they engage in more dynamic, innovative, and higher value-added economic activities. On the other hand, there are certain stagnant regions that still base their economies on agriculture, the exploitation of their natural resources, and the production of laborintensive goods; hence, the changes in their levels of incomes are governed by fluctuations in the price and volume of natural resources.

\footnotetext{
* The authors are grateful to the reviewers' valuable comments that helped to improve significantly this work. The authors readily accept responsibility for the remaining errors. The views and conclusions contained in this article are those of the authors and do not necessarily reflect the point of view of Banco de México. Portions of this research were funded by the Research Support Direction of the University of Guanajuato.

Chávez and Mosqueda are Managers at the Regional Economic Division and Economist, respectively, at Banco de México, Mexico. Gómez-Zaldívar is Full Time Professor in the Department of Economics and Finance at University of Guanajuato, Guanajuato, Mexico. Corresponding Author: M. Gómez-Zaldívar E-mail: manuel.gomez@ugto.org

${ }^{1}$ Mexico has attempted reforms such as joining the General Agreement on Tariffs and Trade (GATT), privatizing state-owned enterprises, signing various foreign trade and investment agreements, and achieving fiscal discipline, among other measures.
}

C) Southern Regional Science Association 2017.

ISSN 1553-0892, 0048-749X (online)

www.srsa.org/rrs 
We aim to broaden the understanding of what determines the level of wealth of Mexico's states and their growth rates by providing an argument based on structural explanations for their relative economic performance during the period 1998-2013. Our justification implies that the distribution or localization of economic activities across the nation helps to explain the diversity of the states' growth rates. We follow Vesti (2015), who argues that the observed disparities in GDP per capita and growth rates depend primarily on the sectoral composition of employment. ${ }^{2}$

To do this, we begin by analyzing the economic structure of the states, identifying their diversity (i.e., the number of economic activities in which they specialize) and the location of economic activities (i.e., the number of states that are specialized in each activity). We then use the method proposed by Hausmann and Hidalgo (2009) (henceforth HH), who argue that it is possible to obtain a measurement of productive capacities (i.e., a measure of economic complexity) from the measures of diversity and location initially estimated. This approach makes it possible to classify each state not only by the variety of activities it specializes in but also in relation to other states that specialize in the same activities. Finally, we show that there is a relationship between the complexity measures calculated and the economic performance of the states. ${ }^{3}$

Our work is closely related to two areas of the literature. First, our study is related to others that attempt to explain the economic performance of Mexico's regions, particularly those that endeavor to define the factors that drive economic growth by estimating growth regressions using either cross-sectional or panel data. There is a plethora of papers that attempt to explain the growth of states in the post-economic liberalization period (the latter half of the eighties onwards), which shows how an assortment of variables have contributed to the growth of Mexico's regions, such as Chiquiar (2005), who argues that since the trade liberalization reforms, the states that have experienced the greatest growth in per capita Gross Domestic Product (GDP) are those more favorably endowed in terms of human and physical capital, and which have better levels of communications and transport infrastructure. Rodríguez-Oreggia (2005) confirms that the growth patterns of these regions in the period 1985-2000 is explained, in part, by human capital, and also suggests an association between public investment and greater growth on the one hand and specialization in export-focused economic activities and higher growth rates on the other. Cabral and Mollick (2012) suggest that the variables trade openness (trade/GDP), foreign direct investment (FDI), and international migration have a strong positive effect on the growth of GDP per capita. Meanwhile, Jordaan and Rodriguez-Oreggia (2012) find that both FDI and spatial readjustments of economic activity have helped drive regional growth. This last study confirms the assertion of Hanson (1998), who argues that after the enactment of the North American Free Trade Agreement (NAFTA) a significant portion of the industry around Mexico City moved to

\footnotetext{
${ }^{2}$ Vesti (2015) states that in 2012 the percentage of the employed population working in the primary sector was 13.6 percent at the national level. However, in some states in the southern region this figure was higher than the national average, such as Chiapas (41 percent), Guerrero (31 percent), and Oaxaca (30 percent). This percentage was below 10 percent in all of the states along the northern border and almost insignificant in the Federal District. Similarly, the percentage of people employed in the manufacturing sector was 15 percent at the national level, yet in most states in the southern region the figure was below 10 percent. In contrast, in Coahuila, Chihuahua, Nuevo León, Guanajuato, and Queretaro the percentage of the employed population in the primary sector was over 20 percent.

${ }^{3}$ Other relevant studies that have also calculated the economic complexity of a country's regions and used this to explain their growth include Poncet and Starosta (2013), Cristelli et al. (2014), Coniglio, Lagravinese and Vurchio (2016), and Zaccaria et al. (2016). These follow the methodology proposed by HH (2009) for calculating economic complexity and use the latter to explain the regional growth observed or to predict future growth.
}

(c) Southern Regional Science Association 2017. 
northern states, which explains the economic success of those states sharing a border with the U.S. ${ }^{4,5}$

The second area of the literature to which our work is related are those studies that measure the localization of economic activities (mostly focusing on manufacturing industries) and regional specialization; see Amiti (1999), Paluzie et al. (2001), Mulligan and Schmidt (2005), Ezcurra et al. (2006), among others. We use an indicator of localization and specialization to construct an index that quantifies the productive capabilities of Mexican states. Our results imply that the distribution or location of economic activities helps to explain, in part, the growth observed in the various different regions of the country. In particular, they indicate that those states that were able to develop economic activities that were more value-added intensive and had higher growth rates during the period under analysis, mainly because they have the productive knowledge to take advantage of the new sources of growth.

The remainder of the article is organized as follows. In Section 2, we describe the so-called "method of reflections," which is used to calculate the economic complexity of the states and of their economic activities; Appendix 1 contains an intuitive explanation of this method. In Section 3 we present the results: i) we show the evolution of the economic complexity of each of the country's states over time (1998, 2003, 2008, and 2013); ii) we provide evidence that allows us to assert that there is a positive relationship between a state's level of economic complexity and its level of wealth; (iii) we show that there is also a relationship between the level of complexity of the economic activities each state specializes in and its level of wealth, and; iv) we present evidence to show that the level of complexity of the states is a determining factor in the growth rates observed in different regions, which we achieve by running a growth regression using panel data, a standard method used in the literature to determine the factors that explain growth. Section 4 contains final remarks.

\section{METHOD FOR ANALYZING REGIONAL COMPLEXITY}

The measure of complexity of states and economic activities is obtained in two steps: i) we estimate a matrix that describes the economic composition of the country's various regions, while at the same time showing the location of the range of economic activities that take place there; ii) using the previously calculated matrix, we apply the method of reflections (MR) to obtain the measures of complexity.

\subsection{Calculation of the matrix that defines the economic structure of the states}

To construct the matrix, $M_{s, a}{ }^{6}{ }^{6}$ we use the definition of the location quotient (LQ) commonly employed in the regional science literature:

$$
L Q_{s, a}=\frac{\frac{p_{s, a}}{\sum_{a=1}^{n} p_{s, a}}}{\frac{\sum_{S=1}^{32} p_{S, a}}{\sum_{S=32, a=n}^{S=1, a=1} p_{S, a}}}
$$

\footnotetext{
${ }^{4}$ Hanson (1998) explains that when industries relocated after NAFTA they sought, in part, to reduce transportation costs to the market was to become most relevant after the agreement - the U.S.

${ }^{5}$ The method employed in studies involving Mexico is similar to that used in others based on county data that identify the factors driving growth, see: Barro (1991), Mauro (1995), Barro (1996), Hansen and Tarp (2001), Bleaney and Nishiyama (2002), Glaeser et al. (2004), Hoover and Pérez (2004), Crespo Cuaresma, Doppelhofer and Feldkircher (2014), among others.

${ }^{6}$ The dimension of the matrix $\mathbf{M}$, is $32 \times n$; where 32 is the number of states in Mexico and $n$ is the number of economic activities.
} 
where $p_{s, a}$ is the number of people employed in state $s$ in economic activity $a$; $\sum_{a=1}^{n} p_{s, a}$ is the total number of people employed in state $s ; \sum_{s=1}^{32} p_{s, a}$ is the total number of people employed in economic activity $a$ throughout the country; $\sum_{s=1}^{32} \sum_{a=1}^{n} p_{s, a}$ is the total number of people employed countrywide.

Each entry of the matrix then is defined as follows: $m_{s, a}=\left\{\begin{array}{c}1 \text { if } L Q_{s, a} \geq L Q^{*} \\ 0 \text { Otherwise }\end{array}\right.$

The results presented in the following section are calculated using a threshold of $L Q^{*}=$ 1.0. This implies that a state $s$ is specialized in an economic activity $a$ if the share of people employed in this activity within the state is equal to or greater than the same activity's nationwide share.

\subsection{Method of Reflections (MR)}

Once the $M_{s, a}$ matrix has been defined, we use it to define our two basic dimensions of relative economic structure by state, with which we compute economic complexity via the MR literature:

$$
\begin{gathered}
\text { Diversification: } \kappa_{s, 0}=\sum_{a=1}^{n} m_{s, a} \\
\text { Ubiquity: } \kappa_{a, 0}=\sum_{s=1}^{32} m_{s, a}
\end{gathered}
$$

Diversification, the initial measure of economic complexity, is a vector that counts the number of economic activities in which each state is specialized. Ubiquity shows the number of states that are specialized in each activity.

The MR consists of calculating iteratively the average value of the prior period's level for the measures of diversification and ubiquity, starting with the initial measures defined in Equations (2) and (3). The iterative process is defined as follows:

$$
\begin{aligned}
& \kappa_{s, N}=\frac{1}{\kappa_{s, 0}} \sum_{a=1}^{n} m_{s, a} \cdot \kappa_{a, N-1} \\
& \kappa_{a, N}=\frac{1}{\kappa_{a, 0}} \sum_{s=1}^{32} m_{s, a} \cdot \kappa_{s, N-1}
\end{aligned}
$$

for $N \geq 1$, where $N$ is the number of iterations. Iterations continue until no further information can be extracted, which according to our definition occurs when the relative ranking of the $\kappa_{S, N}$ variable does not change for three consecutive iterations.

Initially, the complexity of states is given by the measure of diversity, which is in turn enhanced by the information provided by the ubiquity in each of the iterations. Thus, the more diverse and specialized the activities unique to a state are, the higher its complexity ranking will be, as it will also be if it specializes in activities that other states with a more diverse range of activities also specialize in. ${ }^{7}$

\footnotetext{
${ }^{7}$ Appendix 1 presents a hypothetical example to further extend the explanation of the MR.
} 


\section{Figure 1: Diversity and Average Ubiquity of Economic Activities, 2013}

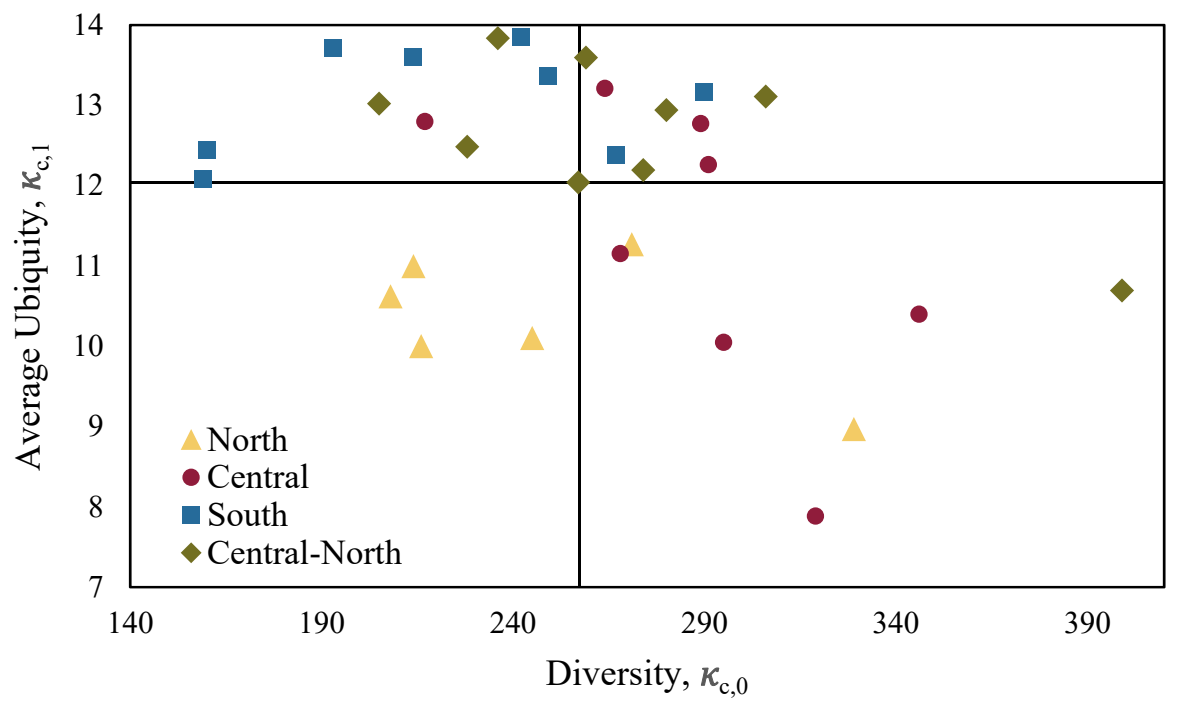

\section{DATA AND RESULTS}

Using data from the economic censuses conducted by the Mexican National Institute of Statistics and Geography (INEGI), ${ }^{8}$ we calculate the economic complexity of states and economic activities based on the number of people employed in each kind of economic activity. For the 1998, 2003, 2008, and 2013 censuses, the total number of economic activities are, respectively, 797, 866, 882 , and 883. An important characteristic that distinguishes this study from $\mathrm{HH}$, the seminal paper in this literature, is that we use data on the employed population while they use international trade data. Therefore, the data we use includes more economic activities, services, and nontradable activities, and thus provides valuable information, as these represent the productive knowledge that an economy has and account for a large portion of an economy's GDP and its employed population. This data set is suitable for our purpose, i.e., the construction of the economic complexity measures, because it helps us characterize the economic structure of the various states.

We begin by illustrating the results of the first iterations computed by using the MR with the 2013 data. Figure 1 shows the number and type of economic activities each state specializes in, and thus gives us an idea of the capabilities of each state. It shows the number of different activities each state is specialized in $\left(\kappa_{c, 0}\right)$ against the average ubiquity of the activities in which it is specialized $\left(\kappa_{c, 1}\right) .{ }^{9}$ The negative correlation between the two variables implies that more diversified states tend to specialize in less ubiquitous activities. ${ }^{10}$ Less diversified states specializing in more ubiquitous activities (upper left-hand quadrant) are found primarily in the

\footnotetext{
${ }^{8}$ Economic activities are classified according to the North American Industry Classification System (NAICS); we use the data at the six-digit level of aggregation.

${ }^{9}$ The higher average ubiquity, the greater the number of states specializing in the same activities as the state concerned.

10 Throughout the article, we discuss the results obtained using the regionalization used by Banco de México. North: Baja California, Chihuahua, Coahuila, Nuevo León, Sonora and Tamaulipas; North-Central: Aguascalientes, Baja California Sur, Colima, Durango, Jalisco, Michoacán, Nayarit, San Luis Potosí, Sinaloa and Zacatecas; Central: Mexico City, State of Mexico, Guanajuato, Hidalgo, Morelos, Puebla, Querétaro and Tlaxcala; South: Campeche, Chiapas, Guerrero, Oaxaca, Quintana Roo, Tabasco, Veracruz, and Yucatán. It is important to clarify that the results do not in any way depend on the regionalization approach employed, which is used merely for descriptive purposes only.
}

(c) Southern Regional Science Association 2017. 
Table 1: Evolution of States' Economic Complexity, 1998-2013

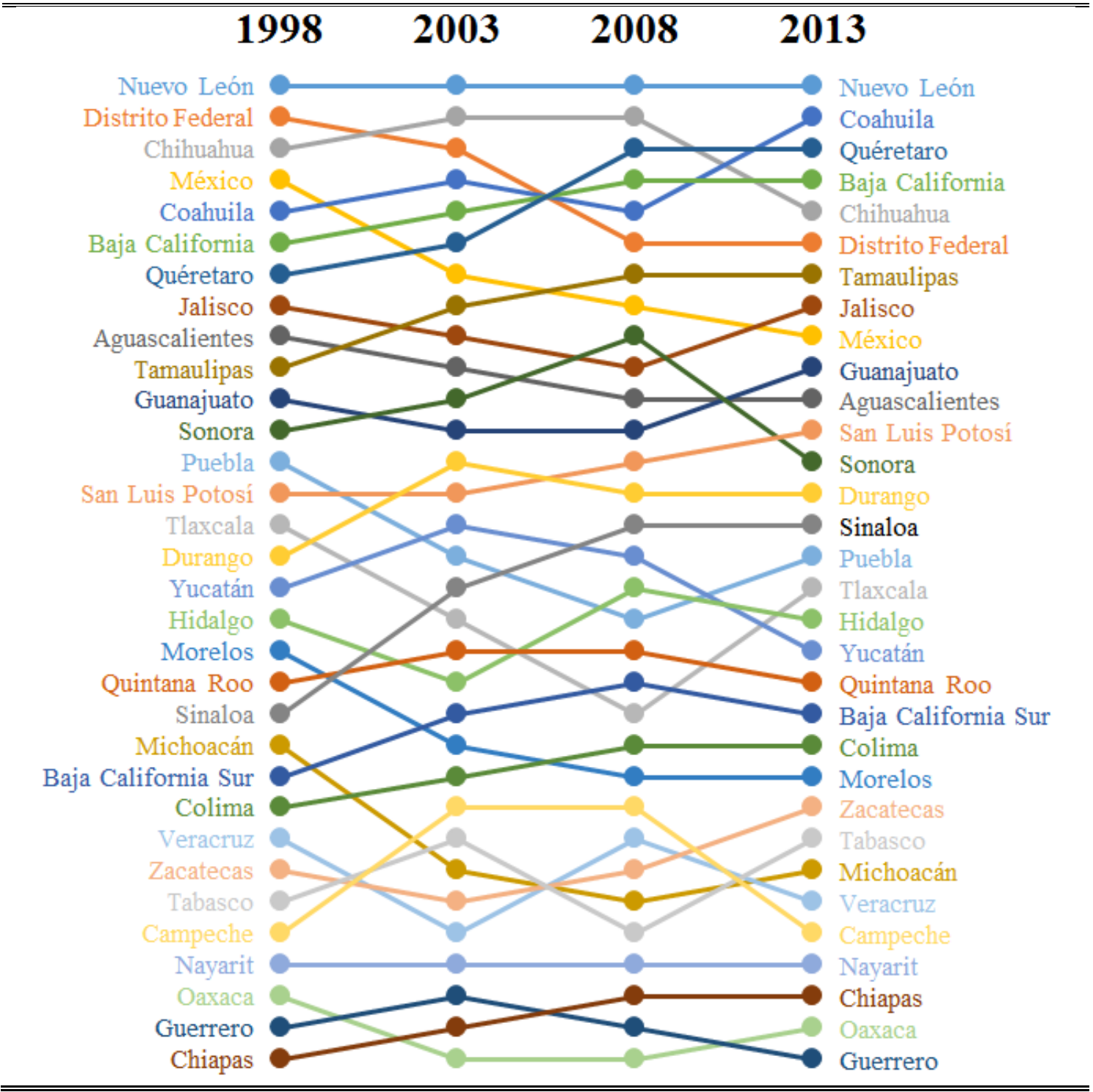

south region. More diversified states specializing in less ubiquitous activities (lower right-hand quadrant) tend to be found in the north and central regions.

\subsection{Complexity of Mexican States}

We classify the states' level of economic complexity for the years 1998, 2003, 2008, and 2013, and then classify these accordingly. Table 1 shows the changes in the complexity classification over the sample period. In order to assess how these rankings change over time, we calculate the rank correlation coefficient between the ranking in 2013 and all the other rankings for the other years. The rank correlation between the 2013 and 1998 ranking is .96; between 2013 and 2003, .97; and between 2013 and 2008, .98. The magnitude of the correlations and the changes 


\section{Map 1: States' Level of Economic Complexity, 2013}

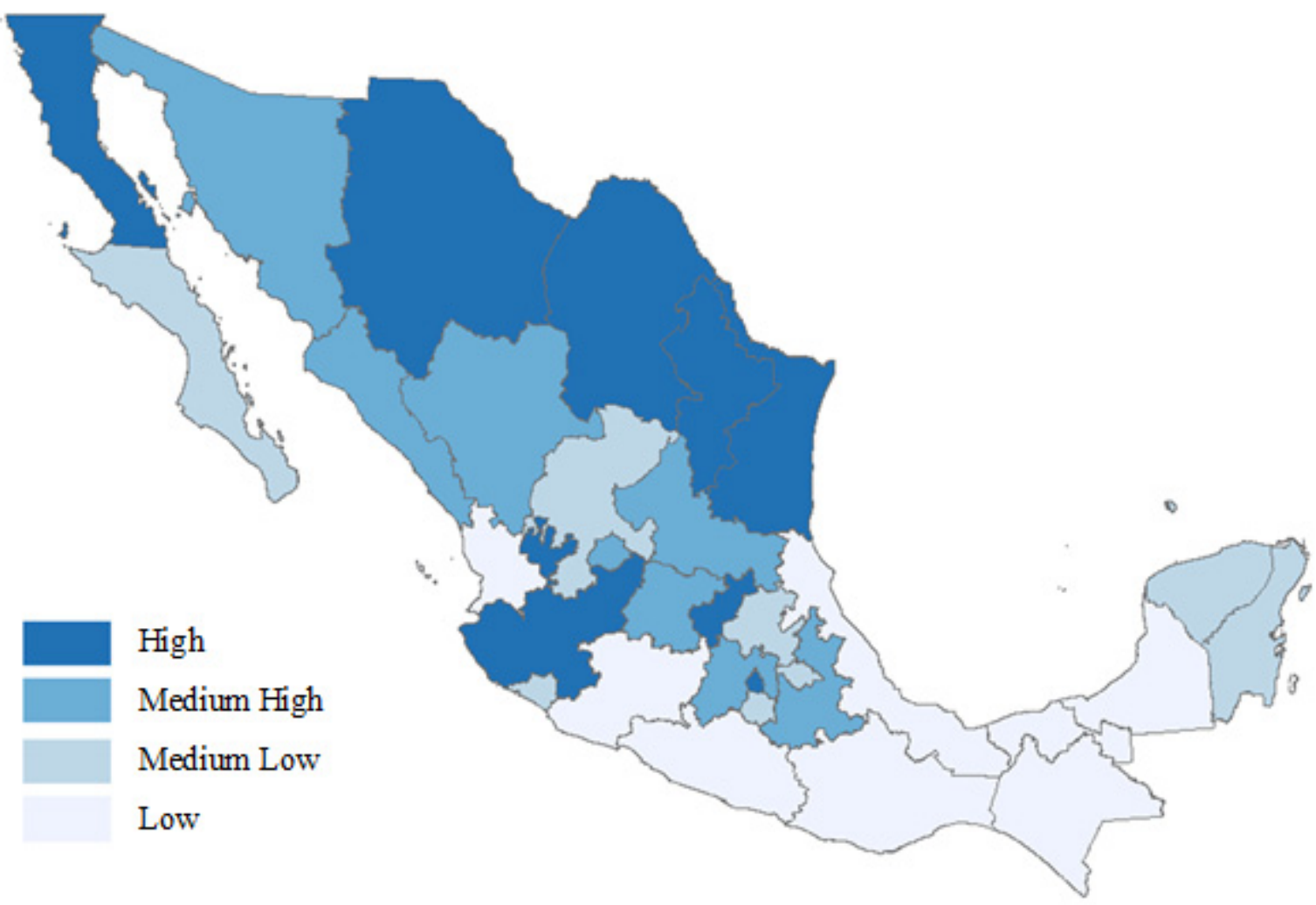

in these suggest that the accumulation of capacities, i.e., the ability to carry out a broader range of economic activities, only occurs slowly over time. ${ }^{11}$

Furthermore, using the results from 2013, we show that the estimated measure of complexity displays a clear regional pattern. Map 1 shows that states in the northern region are among the most complex economies (five out of the six states in this region are in the group comprising the most complex economies). States in the central regions tend to be located at intermediate levels of complexity. Finally, most of the states that belong to the southern region are classified within the group comprised of the least complex economies in the country (six out of eight states are in the lowest part of the classification). ${ }^{12}$

\subsection{Complexity of Mexican States and per capita GDP}

As mentioned previously, the economic complexity measure reflects the productive knowledge embedded in the productive structures of the states. Therefore, the level of GDP per capita is expected to be positively correlated with the estimated level of complexity. In Figure 2, we illustrate the relationship between our measure of complexity and GDP per capita (with and without oil). It is important to note that the estimated level of complexity is far more closely

\footnotetext{
${ }^{11}$ Appendix 2 presents evidence in favor of the robustness of the economic complexity measure. It shows that the rankings are similar when we use different threshold values $(0.1,0.2,0.5,1.0,1.1$, and 1.4) and different levels of aggregation of economic activities (four, five, and six-digits) to construct the matrix $M_{s, a}$.

12 To generate Map 1, we divide the 32 states into four groups of eight, and make the ranking according to their estimated level of complexity.
} 
Figure 2: States' Economic Complexity and GDP per capita, 2013

Panel A. Panel B.

GDP and Complexity GDP (excluding oil) and Complexity

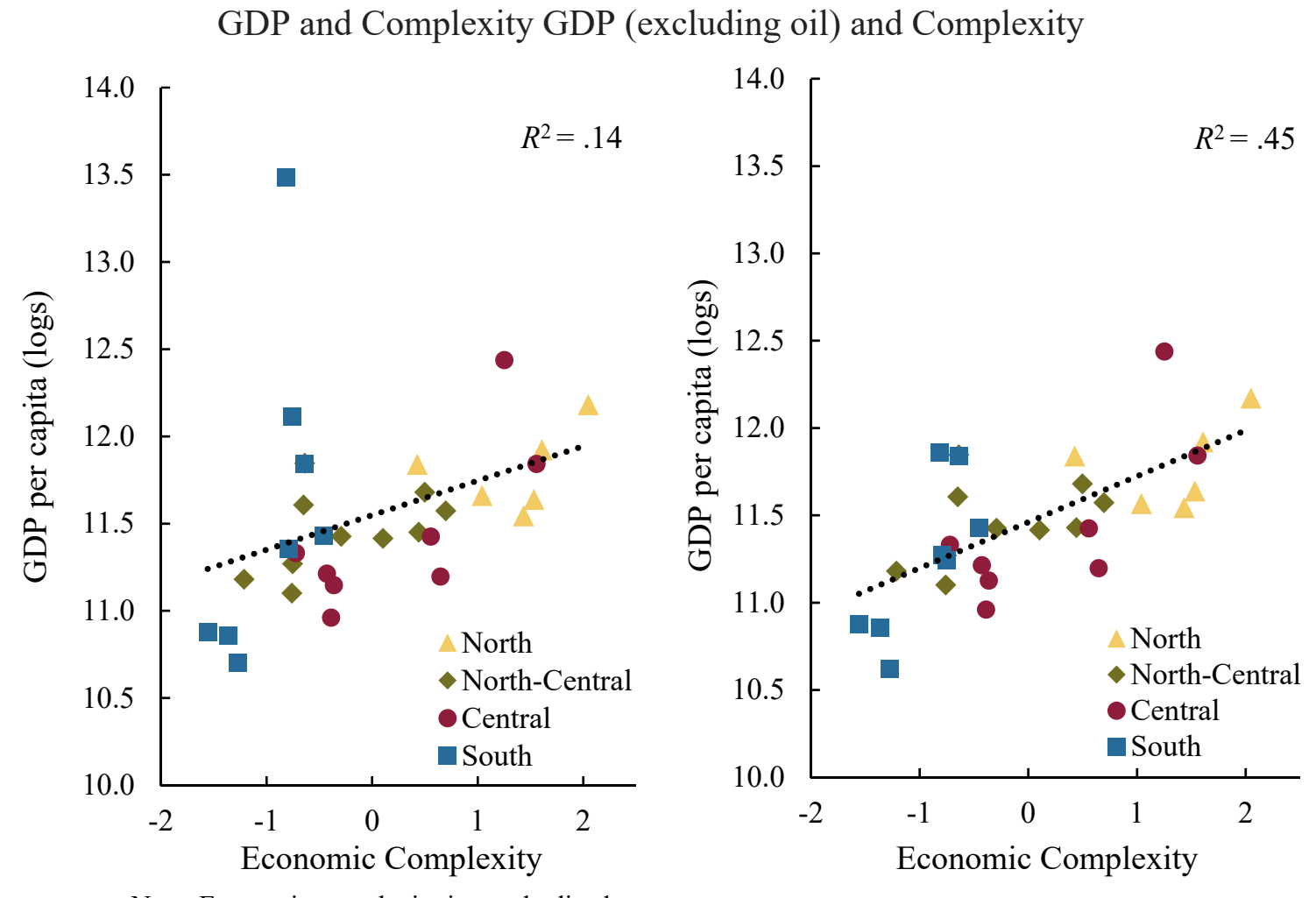

Note: Economic complexity is standardized.

correlated with the per capita GDP that excludes oil. ${ }^{13}$ The oil-producing states are rich, not because of the productive knowledge they possess but because of their geology. Campeche and, to a lesser extent Tabasco, appear to be outliers, suggesting that they are too rich for their level of complexity. The correlation is reflected in the $R^{2}$. In Panel A, with GDP including oil, this measure is only .14. In contrast, when oil mining is excluded (Panel B), economic complexity considerably increases the proportion of the explained variance of the GDP per capita to 45 percent.

Appendix 3 illustrates how the MR computes a better measure of complexity with each additional iteration. The higher the number of iterations, the higher the $R^{2}$ between the measure of complexity and GDP per capita.

\subsection{Complexity of Economic Activities and per capita GDP}

We also calculate the level of complexity of different economic activities. Table 2 shows the ranking of different sectors based on 2013 data. ${ }^{14}$ We find that the most complex sectors are finance and insurance, management of companies and enterprises, and manufacturing. The first two of these are concentrated in Mexico City and employ a small percentage of people (2.4 percent of all workers). Meanwhile, manufacturing is a sector in which participation is very high in most northern states and employs almost a quarter of the total number of people employed nationwide.

\footnotetext{
13 The measure of complexity cannot account for income derived from the exploitation of natural resources. Therefore, it is always going to be more closely correlated with measures of GDP that exclude income derived from this source.

${ }^{14}$ To obtain the ranking, we average the level of complexity calculated for specific activities in each sector.
}

(c) Southern Regional Science Association 2017. 


\section{Table 2: Classification of Economic Sectors according to their Complexity and Percentage of Employed Population per Sector, 2013}

Sectors

Finance and Insurance

Percent of population employed

Management of Companies and Enterprises

Manufacturing

Utilities

Information and Cultural Industries

Administrative and Support, Waste Management and Remediation Services

Professional, Scientific, and Technical Services

Wholesale Trade

Non-Oil Mining

Transportation and Warehousing

Construction

Health Care and Social Assistance

Educational Services

Real Estate and Rental and Leasing

Arts, Entertainment, and Recreation

Other Services

Agriculture, Forestry, Fishing, and Hunting

Retail Trade

Oil Mining

Accommodation and Food Services
2.2

0.2

23.5

1.0

1.3

To understand the relationship between states' GDP per capita and the complexity of economic activities in which each one specializes, we analyze the distribution of employed persons by economic activities, ranked according to their complexity. Figure 3 shows the histogram of people employed by type of economic activity in selected states, where the economic activities are ranked according to their level of complexity. On the one hand, there are certain states, such as those in Panel A, that have a larger percentage of workers employed in more complex activities; hence, their distributions are skewed to the left (negatively skewed). On the other hand, other states, such as those in Panel B, have more people employed in less complex activities and consequently their distributions are skewed to the right (positively skewed). 
Figure 3: Distribution of the Population Employed in Various Economic Activities, Classified according to their Level of Complexity, 2013.

Panel A. States with a large percentage of people employed in more complex activities Nuevo León Coahuila Queretaro
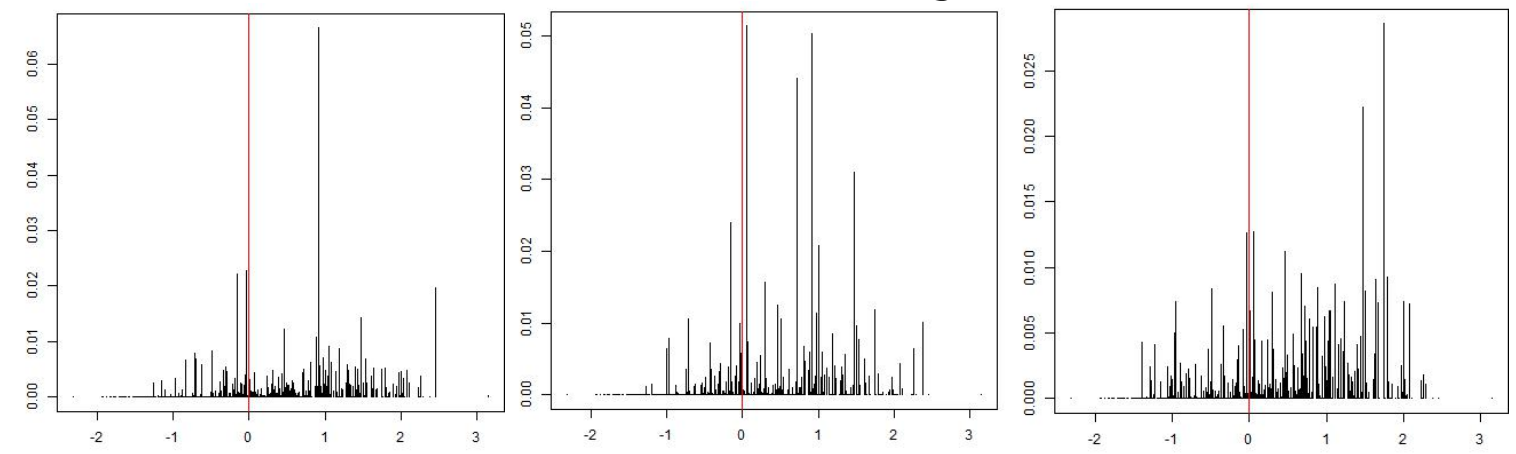

Panel B. States with a large percentage of people employed in less complex activities

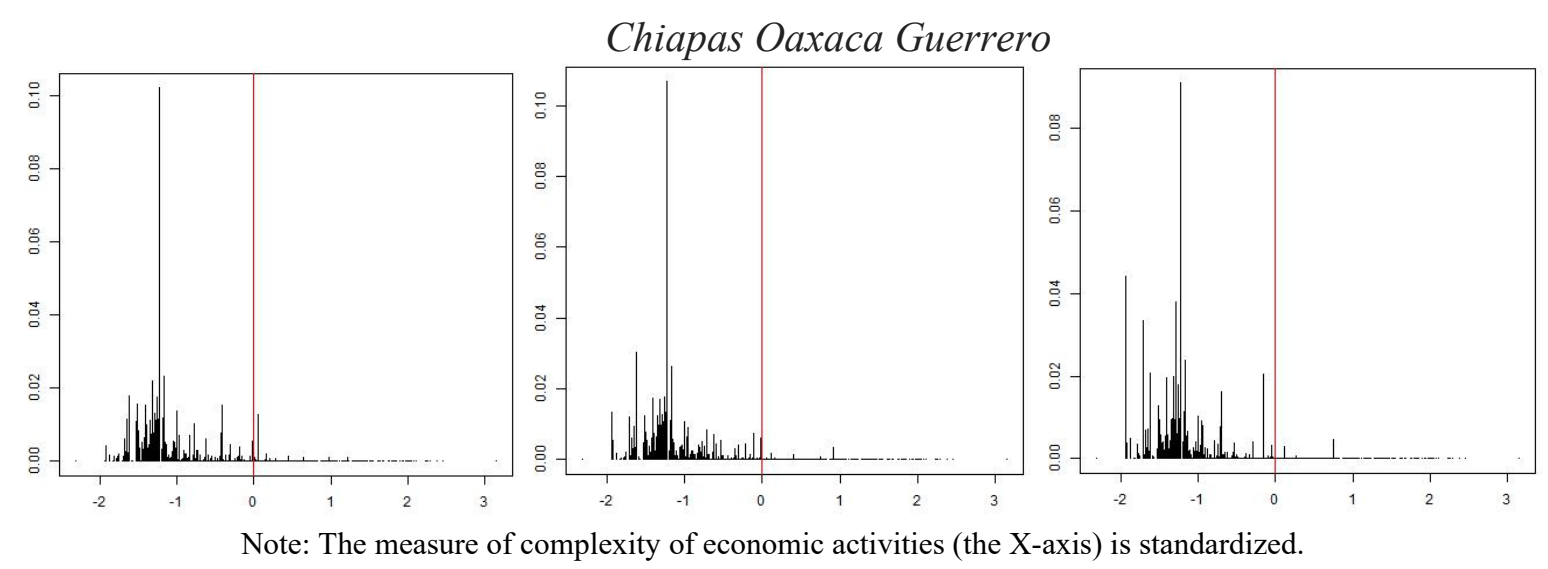

We calculate a measure of the asymmetry of the distribution of employment by economic activities; for this, we use the interquartile asymmetry index. ${ }^{15}$ Those states whose working population is employed in less complex activities will have a positive estimate $(A>0)$, whereas those states whose employed population tends to work in more complex activities will show a negative estimate $(\mathrm{A}<0)$.

Finally, we plot the asymmetry measure along with per capita GDP and find, as shown in Figure 4, a negative relationship between the two. This implies that those states whose working population is employed in less complex activities (positive skewness) have, on average, a lower level of per capita GDP. In contrast, states whose employed population tends to work in more complex activities (negative skewness) have, on average, higher levels of per capita GDP.

As noted previously, our measure of the asymmetry of the distribution of the employed population is far more closely correlated with the per capita GDP that excludes oil. When oil is

\footnotetext{
15 This index measures the asymmetry of the distribution based on the distance between quartiles and takes values between -1 and $1, A=\frac{Q_{3}+Q_{1}-2 Q_{2}}{Q_{3}-Q_{1}}$.
}

(C) Southern Regional Science Association 2017. 
Figure 4: GDP per capita and Skewness of the Distribution of Employed Population by Economic Activities, 2013
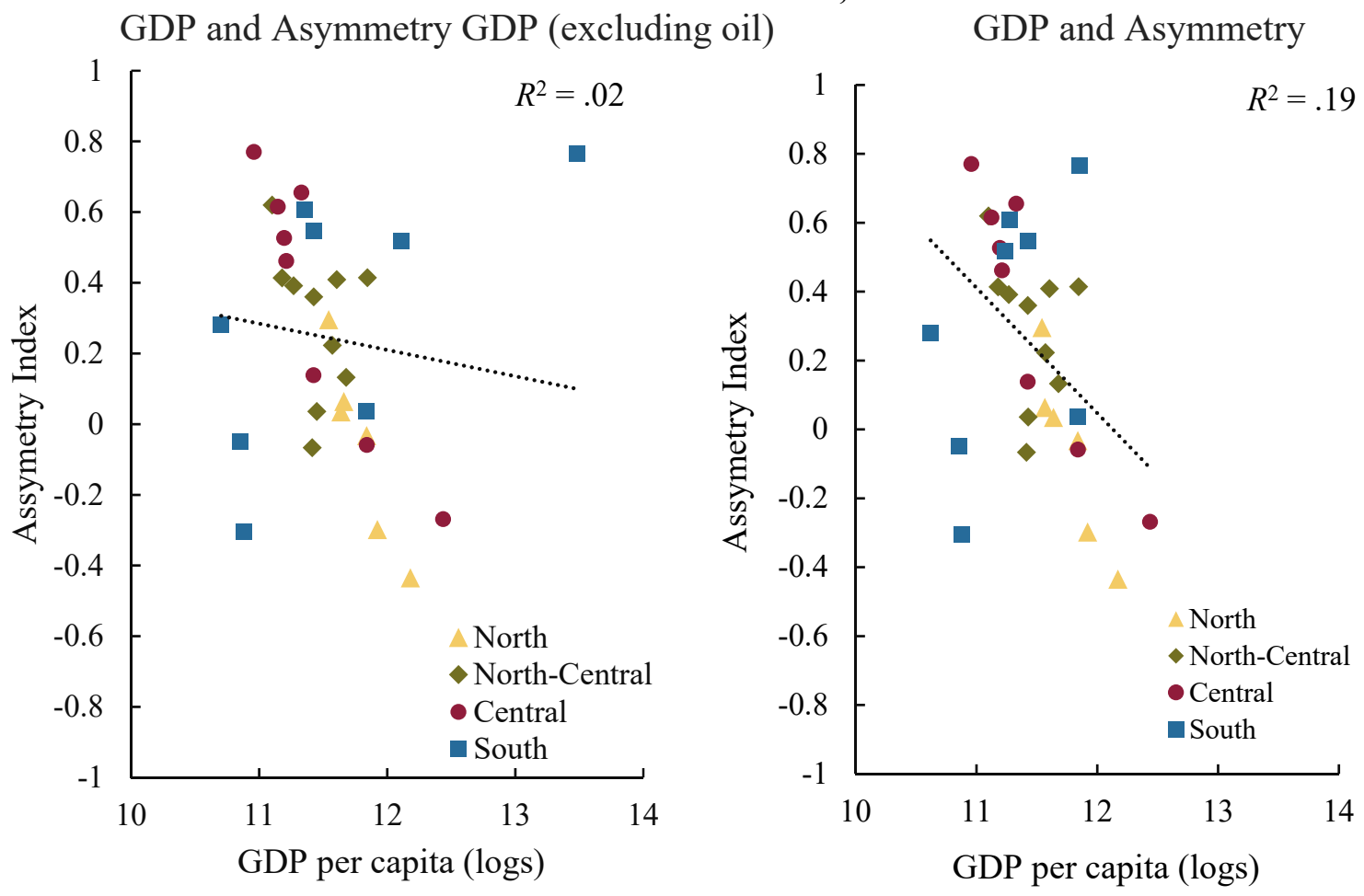

excluded from per capita GDP, the proportion of the explained variance of the GDP per capita increases from 0.02 to 0.19 .

\subsection{States' Economic Complexity and Economic Growth}

The states' economic complexity is also useful to analyze the observed economic growth of the states. To do this, we estimate a growth regression model that has as the dependent variable the average annual growth rate of per capita GDP for the periods 1998-2003, 2003-2008, and 2008-2013. ${ }^{16}$ We include as independent variables the logarithm of initial per capita GDP for each period. This variable is always included in growth regressions because of the convergence hypothesis, which implies that, ceteris paribus, poor economies tend to grow faster than rich ones. The second independent variable included is the states' economic complexity at the beginning of each period; the ability of this variable to predict future economic growth relies on the notion that economies tend towards the per capita GDP that corresponds to the level of productive knowledge they possess. We also include a dummy variable that takes the value of 1 for those states where oil mining represents more than 5 percent of the state's GDP (Campeche, Tabasco, Tamaulipas, Chiapas, and Veracruz), and 0 in all other cases. ${ }^{17}$ Similarly, we include a dummy variable for every five-year period analyzed, which captures those common factors that affected all states in each period. Specifically, the estimated model is:

\footnotetext{
${ }^{16}$ The growth regression - as specified in Equation (6) - is a standard method used in the literature to estimate whether convergence exists and to determine the factors that affect the growth of the economies. This method of empirical estimation has its theoretical basis in neoclassical growth models, such as Solow (1956), Cass (1965), and Koopmans (1965).

17 This variable is included to complement the variable of complexity, given that the measure of complexity cannot explain the income that comes from the exploitation of natural resources.
}

(C) Southern Regional Science Association 2017. 


$$
\gamma_{s, t}=\alpha_{0}+\alpha_{1} d_{1}+\alpha_{2} d_{2}+\alpha_{3} d_{3}+\beta_{0} \log \left(y_{s, t_{0}}\right)+\beta_{1} \text { Comple }_{s, t}+\varepsilon_{s, t}
$$

where $\gamma_{s, t}$ is the states' average GDP per capita growth rates; $d_{1}$ is the dummy variable that identifies oil mining states; $d_{2}$ is the dummy variable for the period 2003-2008; $d_{3}$ is the dummy variable for the period 2008-2013; $y_{s, t_{0}}$ is the states' GDP per capita at the beginning of each period; and Comple $e_{s, t}$ represents their level of complexity. ${ }^{18}$

A state's future growth rate depends on the disparity between its current level of GDP per capita and its level of complexity. States whose level of economic complexity is greater than expected given their observed level of GDP per capita tend to grow faster than those whose level of GDP per capita is high for their complexity level.

Table 3 shows the results of this model. ${ }^{19,20}$ All parameters in Table 3 have the expected sign and, except for the dummy variable that identifies oil-producing states and the dummy for the period 2008-2013, the parameters are all statistically significant. The results clearly suggest that there is a positive correlation between a state's economic complexity and its growth rate, and that those states with a high degree of dependency on the exploitation of natural resources have lower growth rates. The results also show that during the period 2003-2008, the states were positively affected by common factors.

Using the previous results, we predict the states' annual per capita GDP growth rate for the period 2014-2019. To do this, we assume that the factors that affected all states in the period 20082013 will affect them in exactly the same magnitude during the period for which we are predicting

\section{Table 3: Growth Rate of per capita GDP and Economic Complexity} (1998-2003, 2003-2008, and 2008-2013)

\begin{tabular}{lc}
\hline \hline & Variable \\
Constant & $5.500 * * *$ \\
Log GDP per capita, $\left(\beta_{0}\right)$ & $-0.991 * * *$ \\
Economic Complexity, $\left(\beta_{1}\right)$ & $0.407 * * *$ \\
Dummy variable for oil-mining states $\left(\alpha_{1}\right)$ & -0.351 \\
Dummy variable for the period 2003-2008 $\left(\alpha_{2}\right)$ & $1.257 * * * *$ \\
Dummy variable for the period 2008-2013 $\left(\alpha_{3}\right)$ & -0.251 \\
Observations & 96 \\
$R^{2}$ & .35 \\
\hline \hline
\end{tabular}

The symbols $* * *$ denote statistical significance at 1 percent level.

\footnotetext{
${ }^{18}$ This model was estimated using few variables, as in HH (2009), their argument being that if complexity and all the other variables normally included in growth regressions that capture the different capacities of economies (i.e., human capital, various measures of physical capital, institutional quality measures, measures of enforcement of the rule of law, etc.) are controlled for, this last group of variables proves to be redundant.

${ }^{19}$ As suggested by a referee, in Equation (6) we also included controls for the distance from each state to Mexico City and to the U.S. border. Both coefficients are estimated as negative, which implies that a state's growth rate decreases the further away it is from Mexico City and from the U.S. border. Nevertheless, neither coefficient is statistically significant.

${ }^{20}$ The results of estimating Equation (6) including additional controls show that the relevance of the complexity variable is robust. The additional control variables used were relevant in explaining the growth rates of the states in the previous papers applied to Mexico referred to in the introduction. These variables are: average years of schooling, federal investment (percent of GDP), road density, crime, manufacturing output (percent of GDP), and agricultural output (percent of GDP). These results are available upon request.
}

(C) Southern Regional Science Association 2017. 
Figure 5: Future Growth Rates (2014-2019) and Economic Complexity

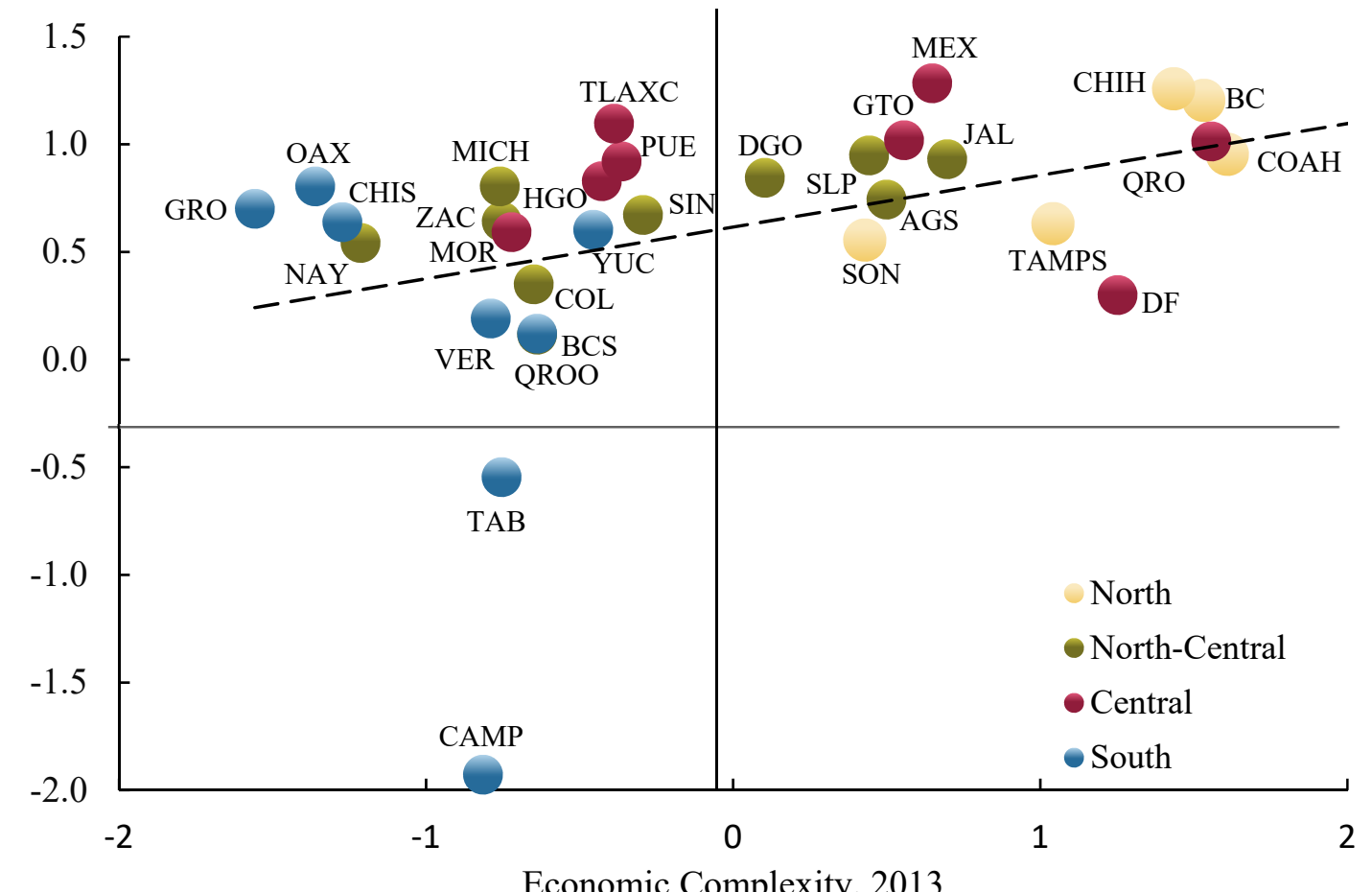

Note: The states' economic complexities (the X-axis) are standardized.

the growth rate. If this assumption is incorrect, it would affect the estimated growth rate of all states in exactly the same magnitude but would not affect the ranking. Similarly, we assume that oil states will not change during the period analyzed.

Figure 5 shows the forecasted annual per capita GDP growth rates. It is clear that states in the north and central region (Mexico State, Chihuahua, and Baja California) have greater growth potential. In contrast, those states that are more specialized in oil production (Campeche and Tabasco) have negative estimated growth rates.

\section{FINAL COMMENTS}

In this study, we present evidence to affirm that the heterogeneous economic composition of Mexican states could help explain the differences in growth patterns across regions. To show this, we calculate the productive knowledge reflected by the dissimilar structures of the states, known as economic complexity. The empirical evidence shows that economic complexity is not distributed evenly among the country's 32 states. Moreover, the productive knowledge of the states is positively correlated with their per capita GDP level and appears to be an important determinant of their average GDP per capita growth rate.

Given that no two regions have the same productive knowledge, their individual growth rates would be maximized by applying public policies aimed at developing their particular productive structure, taking into consideration the specific productive capabilities that already exist in each. This would not only increase the number of economic activities in which regions specialize (making them more diverse), but also would increase the value added of these activities. Mexico is currently striving to boost the development of those regions that have lagged behind,

(C) Southern Regional Science Association 2017. 
the so-called Special Economic Areas (SEZ), the aim being to trigger their economic growth by stimulating the specific productive activities of the regions. The creation of these areas can be considered an example of public policy aimed at encouraging regional economic development by taking into account the particular strengths of each region.

Lastly, the regional pattern revealed by the computed complexity measure suggests the need to incorporate a spatial econometric perspective in the analysis of the determinants of growth (as a number of regional science studies have done). The existence of technology dissemination, agglomeration effects, and so on would imply the existence of significant spillover effects, which would result in the growth rates of states being higher if they are geographically located near more complex economies (which undertake a greater number of, and possibly more sophisticated, economic activities). This will be considered as a possible future line of research.

\section{REFERENCES}

Amity, Mary. (1999) “Specialization Patterns in Europe," Review of World Economics, 135, 573593.

Barro, Robert. J. (1991) "Economic Growth in a Cross Section of Countries," Quarterly Journal of Economics, 106, 407-443.

(1996) Determinants of Economic Growth: a Cross-Country Empirical Study. MIT Press: Cambrige, MA.

Bleaney, Michael and Akira Nishiyama. (2002) "Explaining Growth: A Contest between Models," Journal of Economic Growth, 40, 43-56.

Cabral, Rene and Andre V. Mollick. (2012) "Mexico's Regional Output Convergence after NAFTA: A Dynamic Panel Data Analysis," Annals of Regional Science, 48, 877-895.

Cass, David. (1965) "Optimum Growth in an Aggregative Model of Capital Accumulation," Review of Economic Studies, 32, 233-240.

Chiquiar, Daniel. (2005) “Why Mexico’s Regional Income Convergence Broke Down,” Journal of Development Economics, 77, 257-275.

Coniglio, Nicola D., Raffaele Lagravinese, and Davide Vurchio. (2016) "Production Sophisticatedness and Growth: Evidence from Italian Provinces before and During the Crisis, 1997-2013," Cambridge Journal of Regions, Economy and Society, 9, 423-442.

Crespo Cuaresma, Jesus, Gernot Doppelhofer, and Martin Feldkircher. (2014) "The Determinants of Economic Growth in European Regions,” Regional Studies, 48, 44-67.

Cristelli, Matthieu, Andrea Tacchella, Andrea Zaccaria, and Luciano Pietronero. (2014) "Growth Scenarios for Sub-Saharan Countries in the Framework of Economic Complexity." Munich Personal Repec Archive No. 71594.

Ezcurra, Roberto, Pedro Pascual, and Manuel Rapún. (2006) "Regional Specialization in the European Union," Regional Studies, 40, 601-616.

Glaeser, Edward L., Rafael LaPorta, Florencio López-de-Silanes, and Andrei Shleifer. (2004) “Do Institutions Cause Growth?” Journal of Economic Growth, 9, 271-303.

Hansen, Henrik and Finn Tarp. (2001) "Aid and Growth Regressions," Journal of Development Economics, 64, 547-570.

(c) Southern Regional Science Association 2017. 
Hanson, Gordon H. (1998) "Regional Adjustment to Trade Liberalization," Regional Science and Urban Economics, 28, 419-444.

Hausmann, Ricardo and César A. Hidalgo. (2009) "The Building Blocks of Economic Complexity," Proceedings of the National Academy of Sciences, 106, 10570-10575.

Hoover, Kevin D. and Stephen J. Perez. (2004) "Truth and Robustness in Cross-Country Growth Regressions," Oxford Bulletin of Economics and Statistics, 66, 765-98.

Jordaan, Jacob A. and Eduardo Rodriguez-Oreggia. (2012) "Regional Growth in Mexico Under Trade Liberalization: How Important are Agglomeration and FDI?" Annals of Regional Science, 48, 179-202.

Koopmans, Tjalling C. (1965) "On the Concept of Optimal Economic Growth," Pontificiae Academiae Scientiarum Scripta Varia, 28, 225-300.

Mauro, Paolo. (1995) “Corruption and Growth,” Quarterly Journal of Economics, 110, 681-712.

Mulligan, Gordon F. and Charles Schmidt. (2005) “A Note on Localization and Specialization," Growth and Change, 36, 565-576.

Paluzie, Elisenda, Jordi Pons, and Daniel A. Tirado. (2001) "Regional Integration and Specialization Patterns in Spain,” Regional Studies, 35, 285-296.

Poncet, Sandra and Felipe Starosta de Waldemar. (2013) "Economic Complexity and Growth, Evidence from China," Revue Économique, 64, 495-503.

Rodríguez-Oreggia, Eduardo. (2005) "Regional Disparities and Determinants of Growth in Mexico," Annals of Regional Science, 39, 207-220.

Solow, Robert M. (1956) “A Contribution to the Theory of Economic Growth," Quarterly Journal of Economics, 70, 65-94.

Vesti, Gianfranco. (2015) “Diagnóstico del Desarrollo Regional: México,” Colección Estudios No. 13, Eurosocial, Programa para la Cohesión Social en América Latina y la OECD.

Zaccaria, Andrea, Matthieu Cristelli, Roland Kupers, Andrea Tacchella and Luciano Pietronero. (2016) "A Case Study for a New Metrics for Economic Complexity: The Netherlands," Journal of Economic Interaction and Coordination, 11, 151-169. 


\section{APPENDIX 1}

We present a hypothetical example comprised of four economies (A, B, C, and D) and four economic activities $(1,2,3$, and 4), for which we assume the following values for People Employed,

\begin{tabular}{|c|c|c|c|c|}
\hline & \multicolumn{4}{|c|}{ Economic Activity } \\
\hline & 1 & 2 & 3 & 4 \\
\hline$A$ & 100 & 250 & 1000 & $1000^{\circ}$ \\
\hline States $B$ & 1500 & 500 & 150 & 150 \\
\hline & 400 & 0 & 1200 & 470 \\
\hline$D$ & 850 & 0 & 70 & 2000 \\
\hline
\end{tabular}

To construct the matrix $M_{s, a}$, we use the definition of LQ from Equation (1); the matrix that shows which activities each economy specializes in is as follows:

$$
M_{s, a}=\left[\begin{array}{llll}
0 & 1 & 1 & 1 \\
1 & 1 & 0 & 0 \\
0 & 0 & 1 & 0 \\
0 & 0 & 0 & 1
\end{array}\right]
$$

according to Equations (2) and (3) that define diversity and ubiquity from the matrix $M_{s, a}$. The diversity of each economy is the sum of the corresponding row or the number of economic activities in which it specializes. The ubiquity of each economic activity is the sum of the corresponding column or the number of economies that specialize in the activity concerned. Hence, in this example, ubiquity and diversity are as follows:

$$
\text { Diversity } \left.\left(\kappa_{s, 0}\right)=\left[\begin{array}{l}
3 \\
2 \\
1 \\
1
\end{array}\right] \begin{array}{l}
A \\
C
\end{array}\right] \quad \text { Ubiquity }\left(\kappa_{a, 0}\right)=\left[\begin{array}{l}
1 \\
2 \\
2 \\
2
\end{array}\right] \begin{gathered}
1 \\
2 \\
3 \\
4
\end{gathered}
$$

State $\mathrm{A}$ is the most diverse because it specializes in three economic activities (activities 2, 3 , and 4), while state $\mathrm{B}$ specializes in just 2 (activities 1 and 2) and states $\mathrm{C}$ and $\mathrm{D}$ in just one (activities 3 and 4, respectively). The least ubiquitous economic activity is 1 (only state B specializes in it), while activities 2,3 , and 4 have a ubiquity score of 2 (there are two states that specialize in each of these).

The diversity of A, B, C, and D is the first approximation to the complexity measure of each of the economies under analysis. This first measurement will be gradually refined using the information provided by the ubiquity result, according to the iterative method shown by Equations (4) and (5). On the one hand, the higher a state's initial diversity, the greater level of economic complexity it will have. On the other, ubiquity plays two multiple roles because not only is the ubiquity of the activities in which each state specializes important, but also the ubiquity of the activities in which all the other states specialize.

The following is a step-by-step explanation of how the higher iterations are calculated. We begin by calculating the first iteration of Equation (4); this shows that the matrix $M_{s, a}$ has to be multiplied by the initial ubiquity vector and divided by the initial values for diversity: 


$$
\begin{gathered}
\kappa_{s, 1}=\frac{1}{\kappa_{s, 0}} \sum_{a=1}^{4} m_{s, a} \cdot \kappa_{a, 0} \\
\kappa_{s, 1}=\left[\begin{array}{llll}
0 & 1 & 1 & 1 \\
1 & 1 & 0 & 0 \\
0 & 0 & 1 & 0 \\
0 & 0 & 0 & 1
\end{array}\right] \cdot\left[\begin{array}{l}
1 \\
2 \\
2 \\
2
\end{array}\right]=\left[\begin{array}{c}
(2+2+2) / 3 \\
(1+2) / 2 \\
2 / 1 \\
2 / 1
\end{array}\right]=\left[\begin{array}{c}
2 \\
1.5 \\
2 \\
2
\end{array}\right]
\end{gathered}
$$

Meanwhile, the first iteration of Equation (5) would read as follows:

$$
\begin{gathered}
\kappa_{a, 1}=\frac{1}{\kappa_{a, 0}} \sum_{s=1}^{4} \kappa_{s, 0} \cdot m_{s, a} \\
\kappa_{a, 1}=\left[\begin{array}{llll}
3 & 2 & 1 & 1
\end{array}\right] \cdot\left[\begin{array}{llll}
0 & 1 & 1 & 1 \\
1 & 1 & 0 & 0 \\
0 & 0 & 1 & 0 \\
0 & 0 & 0 & 1
\end{array}\right]=\left[\begin{array}{c}
(2) / 1 \\
(3+2) / 2 \\
(3+1) / 2 \\
(3+1) / 2
\end{array}\right]=\left[\begin{array}{c}
2 \\
2.5 \\
2 \\
2
\end{array}\right]
\end{gathered}
$$

Lastly, we conclude this illustrative example of how the complexity measure is calculated with the second iteration of Equation (4), ${ }^{21}$ which uses the values calculated from the first iteration of Equation (5):

$$
\begin{gathered}
\kappa_{s, 2}=\frac{1}{\kappa_{s, 0}} \sum_{a=1}^{4} m_{s, a} \cdot \kappa_{a, 1} \\
\kappa_{s, 2}=\left[\begin{array}{llll}
0 & 1 & 1 & 1 \\
1 & 1 & 0 & 0 \\
0 & 0 & 1 & 0 \\
0 & 0 & 0 & 1
\end{array}\right] \cdot\left[\begin{array}{c}
2 \\
2.5 \\
2 \\
2
\end{array}\right]=\left[\begin{array}{c}
(2.5+2+2) / 3 \\
(2+2.5) / 2 \\
2 / 1 \\
2 / 1
\end{array}\right]=\left[\begin{array}{c}
2.16 \\
2.25 \\
2 \\
2
\end{array}\right]
\end{gathered}
$$

In this example, state $\mathrm{A}$ is the most diverse, activity 1 the least ubiquitous, and state $\mathrm{B}$ the most complex, as shown by our calculations of economic complexity:

$$
\kappa_{s, 2}=\left[\begin{array}{c}
2.16 \\
2.25 \\
2 \\
2
\end{array}\right] \begin{gathered}
A \\
B \\
D
\end{gathered}
$$

State B is more complex than state A, even though it is initially less diverse. There are various reasons for this. Firstly, state $B$ is the only one specializing in activity 1, which implies that it has certain specific capabilities that no other state has. Secondly, states A and B specialize in activity 2, which implies that they share the capabilities required to develop that activity. Thirdly, state A also specializes in activities 3 and 4, therefore it must have certain capacities that state B does not. Nevertheless, state B is the most complex, because the method recognizes that the capabilities that state B has and which state A does not are more sophisticated than those that state A has and state B does not. This occurs because the capabilities that state A has and which

\footnotetext{
${ }^{21}$ Although, as specified previously, the iterations continue until the relative ranking of the $\boldsymbol{\kappa}_{S, N}$ variable remains unchanged for three consecutive iterations.
}

(C) Southern Regional Science Association 2017. 
state B does not are shared by states C and D, the least diverse states that are specialized in the most ubiquitous activities.

\section{APPENDIX 2}

Given that LQs are very sensitive to scale and the use of a threshold of 1 could be considered arbitrary, as a robustness check we compute the states' economic complexity using different threshold values and different levels of aggregation of economic activities. Then, we use these new rankings to calculate the rank correlations between the ranking we obtained using the threshold of 1 (in Table 1) and the new rankings obtained using different thresholds $(0.1,0.2,0.5$, $1.1,1.3$, and 1.4) and different levels of aggregation of economic activities (four, five, and six digits). ${ }^{22}$

As the results in Table A2.1 shows, the economic complexity ranking is robust, both to different thresholds and to different levels of aggregation of economic activities (four, five, and six digits). The rank correlation coefficient takes values between -1 and 1 . As can be observed, all values are above .8 , which implies that, for every single case, the two pairs of rankings being compared are similar.

Table A2.1: Threshold Values

\begin{tabular}{|c|c|c|c|c|c|c|}
\hline \multicolumn{7}{|c|}{2014} \\
\hline & 0.1 & 0.2 & 0.5 & 1.1 & 1.3 & 1.4 \\
\hline 4-digit & .870 & .897 & .953 & .965 & .944 & \\
\hline 5-digit & .875 & .892 & .948 & .984 & .980 & \\
\hline 6-digit & .850 & .886 & .897 & .976 & .984 & .967 \\
\hline \multicolumn{7}{|c|}{2009} \\
\hline & 0.1 & 0.2 & 0.5 & 1.1 & 1.3 & 1.4 \\
\hline 4-digit & .843 & .858 & .936 & .989 & & \\
\hline 5-digit & .866 & .874 & .939 & .993 & .977 & \\
\hline 6-digit & .800 & .841 & .904 & .992 & & \\
\hline \multicolumn{7}{|c|}{2004} \\
\hline & 0.1 & 0.2 & 0.5 & 1.1 & 1.3 & 1.4 \\
\hline 4-digit & .832 & .844 & .910 & .987 & .974 & .966 \\
\hline 5-digit & .811 & .852 & .922 & 993 & .974 & .970 \\
\hline 6-digit & .812 & .861 & .928 & .994 & .976 & \\
\hline
\end{tabular}

\footnotetext{
${ }^{22}$ In some cases, for high thresholds (1.3 and 1.4), most values of the binary matrix are zero, which implies that economic complexity cannot be calculated.
}

(c) Southern Regional Science Association 2017. 


\section{APPENDIX 3}

The graphs below show the measures of complexity resulting from different iterations and the per capita GDP (excluding oil). It is clear that correlation $\left(R^{2}\right)$ between GDP and economic complexity is greater the higher the number of the iteration.

Figure A3.1: Per capita GDP and Initial Iterations to Calculate Complexity Panel A. Panel B.
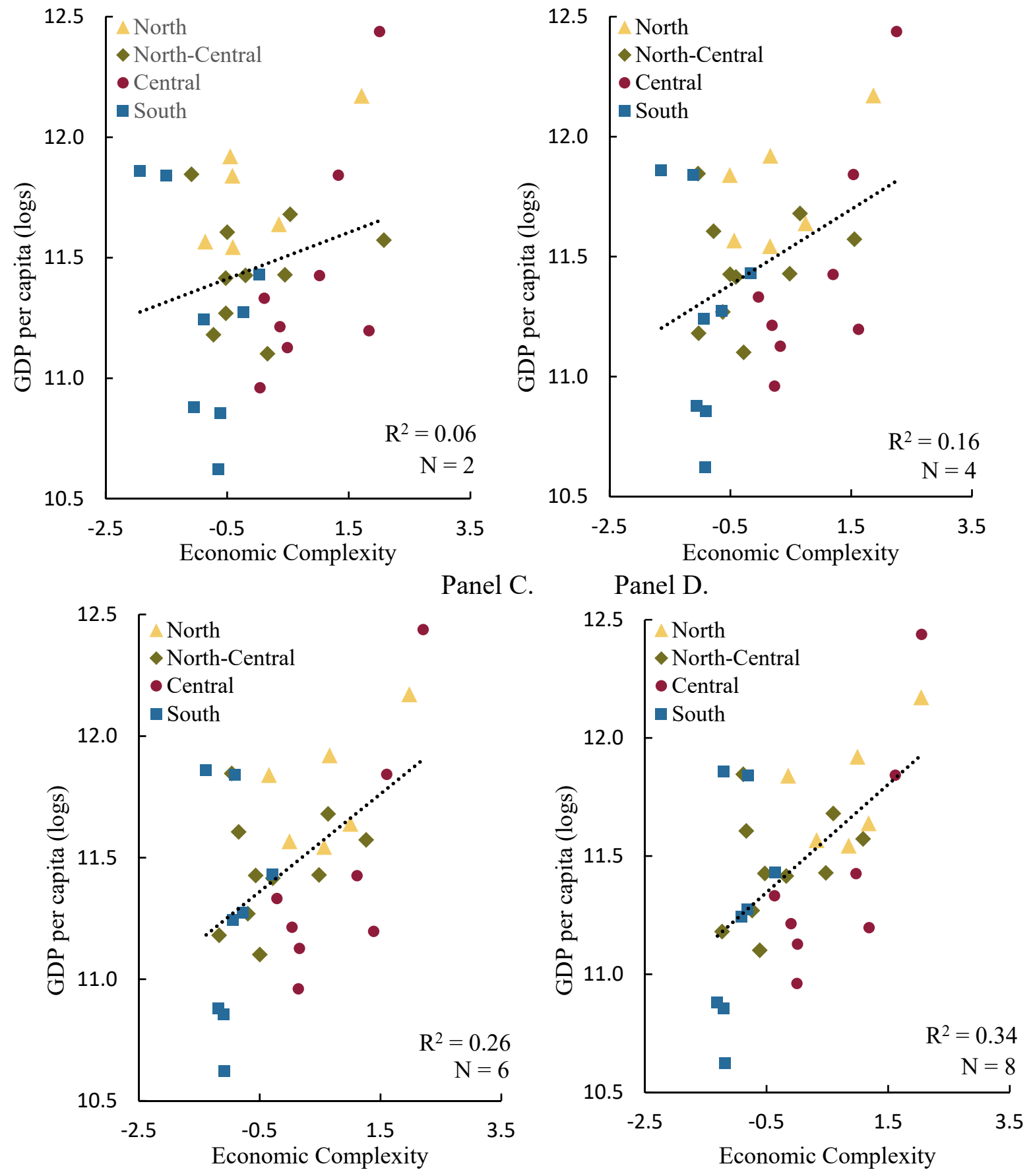

(C) Southern Regional Science Association 2017. 